\title{
TRATAMIENTO SOCIAL PENITENCIARIO: EN BUSCA DE NUEVOS PARADIGMAS ${ }^{1}$
}

\author{
Víctor I. García Toro*
}

\section{Introducción}

$\mathrm{C}$

on frecuencia, asumir compromisos como el de escribir un artículo sobre esta temática, no necesariamente significa el tener pleno conocimiento y menos consciencia cabal de sus implicaciones. Concretamente implicó en una serie de eventos y circunstancias que a los efectos del mismo podríamos llamar de la metodología a través de la cual se dio este proceso. Por metodología entendemos la forma, con frecuencia científica, a través del cual se provee de estructura y forma a un proceso, para obtener un producto. O sea, se sistematiza la forma de obtener el mismo.

Esta metodología significó aceptar comenzar el proceso abriendo el gavetero cerebral y buscar los contenidos de las gavetas, lo que podríamos llamar de desarrollo de un inventario de contenidos y significados relacionados al tema de tratamiento social institucional, datos éstos que se remontan desde 1964 al presente. De modo que fue algo así, como comenzar a auscultarme, a través

${ }^{1}$ Trabajo presentado por el Dr. Víctor I. García Toro en el Congreso de Derecho Penal, Colegio de Abogados, Santurce, Puerto Rico, 15-18 de junio de 1999.

*Catedrático, Escuela Graduada de Trabajo Social, Universidad de Puerto Rico 
de un proceso de crecimiento que hasta hoy no ha concluido. A propósito, otras gavetas, o mejor dicho "CD Rooms" se añadieron a las existentes en el proceso de concluir el trabajo. Siendo así, con frecuencia uno se pregunta qué va a hacer con tanta información almacenada.

Luego de ordenar esa dimensión de la metodología, pasé a descubrir lagunas, actualizar datos, confirmar paradigmas, rechazar otros y a procurar nuevos conocimientos, con el propósito de mantenerme actualizado. Esto a su vez significó el dividir sabiamente mi tiempo, entre las tareas de dirigir una facultad y leer como un desesperado un caudal de nuevas aportaciones al campo del conocimiento de tratamiento social, derecho penal, sociología, criminología, trabajo social y otras, ya dentro de la perspectiva del Congreso.

Para suplir estas fases decidí que también dialogaría con colegas y personas reconocidas en el campo de criminología y haría unas visitas. Así fue, dialogué con colegas, les inquirí sobre sus percepciones y junto a ellos conseguí percibir algo muy curioso y reconfortante. Todavía mis nociones sobre el tema estaban acutalizadas y tenían vigencia. Así que decidí ir a las visitas e hice las llamadas de práxis. Reconocimos voces y acordamos fechas para la visita.

Mi visita fue a la Penitenciaría Estatal, donde inicié mi carrera en este campo, allá para los años de 1964 cuando Don Porfirio Díaz, reconocido Trabajador Social, se desempeñaba en esa institución. Fue un viaje de rescate de recuerdos e imágenes, verificación de espacios y gentes, constatación de novedades programáticas y concretamente de nuevo, un choque con la dura realidad de lo que significa, en este caso en particular, ser hombre y estar preso. Les narraré brevemente un incidente que volvió a recordarme de mi compromiso con la justicia y la criminología desde la perspectiva de Trabajo Social:

Al entrar al Monoloro y pasar hacia el área residencial para visitar una galera, fuimos llamados por un presidiario que se nos acercó, provocando inmediatamente el alerta de los guardias y nos dijo:

-Con el permiso, Mister Conde, habló dirigiéndose al compañero jefe de los Socio-penales que me acompañaba, ime podría escuchar un momento? 
-Como no, dime qué pasa...

-Pues sabe, Sr. Conde, no sé leer ni escribir, comentó el preso bajando la cabeza y exprimiendo el "mapo" en el balde....

-Bueno, pero por qué me dices eso, ¿́cuál es el problema?

- Es que yo quería participar del Programa "Aprendamos a vivir sin Violencia" y no me aceptaron por eso. Me pareció injusto, no necesito leer ni escribir para escuchar y participar, no le parece....

- Aníbal me miró, con una complicidad conocida de años, suspiró profundamente y le respondió al preso...

-Estoy 100 por ciento de acuerdo contigo, haré lo posible para que participes de ese programa. A propósito, muchos internos participaron. Te ayudaré en eso, no te preocupes.

-Gracias "Mister", respondió el joven preso y continuó limpiando el piso, con una amplia sonrisa estampada en su rostro.

Continuó su tarea de guiarme y nos dirigimos a una galera cuyas celdas permanecían abiertas y Conde me comentó que se dejaban abiertas porque como había dos internos en el pasillo podían tener problemas por causa del espacio requerido para los presos por las autoridades federales y estatales. Así constaté, que el caso Morales Feliciano nos perseguía, para bien de los presos.

Observé la población de hombres de media edad, uno pintando y otros mirándonos cabizbajos, como con vergüenza de ser vistos. Un anciano en el pasillo nos gesticuló un saludo y continuó leyendo. Celdas chicas, ordenadas, limpias e insuficientes. Salí de allí como siempre, deprimido y preocupado. Percibe uno que en el ambiente correccional, algunas cosas no cambian y por qué el continuo fracaso de las prisiones ha alcanzado crisis sin límites (Skatnicki, 1998).

Ya fuera del Monoloro, volví a la realidad externa; el Tren Urbano marcando sus espacios frente al Presidio y los presidiarios mirando de lejos el progreso que a pesar de estar tan cerca y no les toca. Recordé entonces, las palabras del Prof. Fernando Picó (1994) quien en su último libro nos comentaba que la historia de los presidiarios de este país, era la historia de la marginación social, asi reinicié este proceso, con los pies en la tierra, adentrándome más en la realidad puertorriqueña donde se inserta ese tratamiento social del cual pasamos a exponer. 


\section{Tratamiento social penitenciario: variables intervinientes}

Referirse a tratamiento social penitenciario arrastra consigo toda una serie de debates entre conceptualizaciones, filosofías, teorías, políticas sociales y paradigmas entre los cuales indiscriminada y dinámicamente hombres, mujeres, jóvenes de ambos sexos y sus familias se ven severamente afectados. Todos ellos son, junto a sus víctimas y la comunidad, nuestro centro de interés, lo que lo hace amplio, complejo y retante. De la misma forma reciben el impacto del control social vigente en la sociedad y esto dice respecto a profesionales de derecho, criminólogos, sociólogos y a las ciencias sociales de la conducta como lo son psicología, trabajo social y otras (Platt, 1994). Las implicaciones de la noción de control social y sus repercusiones, son un reto con el cual hemos lidiado por décadas que requiere nuevos enfoques y aportes desde otras perspectivas novedosas donde se ausculten inclusive las percepciones de los presidiarios, los marginados y los discriminados. Sus percepciones basadas en sus propias experiencias vividas, más que otras, serían la evaluación más fiel de cómo funciona para ellos(as) y los afecta esa propuesta de control del Estado.

Cuando hablamos de control social nos referimos a cómo el Estado, a través de sus diversas estructuras, da forma a través de leyes a políticas sociales que a su vez, a través de programas y propuestas consiguen imprimir en la sociedad los controles necesarios para su funcionamiento, o sea, sus mecanismos de control (Bridges, Meyers, 1994).

Esta noción de control social, a pesar de no estar claramente explicitada en nuestra sociedad como un debate, lo es de modo incipiente e incide en la legitimación de la política gubernamental actual de "Mano Dura contra el Crimen" y sus implicaciones para el Derecho Penal, el Sistema de Justicia y el Correccional, en específico en términos de tratamiento social penitenciario. Dicha política, iniciada en los años ‘ 60 en el contexto de los Estados Unidos, llega a la Isla con un ímpetu moderado en la década de los 70 y adquiere un ímpetu insospechado en el final de la década pasada y en ésta, con una insistencia avasalladora, evidenciando que su campo de acción abarca el total de la sociedad, yendo desde la invasión de comunidades hasta el control de drogas en las escuelas y el desasociego en las instituciones penales del país. Al así hacerlo, consiguió algo que no se propuso inicialmente y que historiadores 
y autores como Platt (1994) clasificaron como una "intervención familiar", a través del control social del Estado. El referido autor, se cuestiona las bases de donde ese control social consigue tener tal impacto y poder. Con frecuencia la Dra. Trina Rivera de Ríos (1990) nos habla del impacto de la crisis carcelaria en más de un millón de personas y el pueblo no se percata de la seriedad del problema para las familias y las comunidades.

Para otros como Bridges \& Meyers (1994), estos mecanismos de la sociedad, entre los cuales el control social sobre el crimen y su tratamiento es nuestro interés, promueven el orden económico, político y social de la sociedad. Para otros, según estos autores, es una función directa de la desigualdad. Esto es así, visto que incide desventajosamente sobre las vidas de grupos pobres y marginados de nuestra sociedad, con gran violencia y como comentaba Platt, sobre todos en la sociedad de una forma u otra. En ambos, la desigualdad es evidente.

Lo interesante es no dejar pasar desapercibido que una percepción real y gritante es, en qué medida este control social y las políticas que lo concretan a través de programas, reflejan nuestra sociedad. Tal vez, a nosotros como estudiosos de este fenómeno, debería preocuparnos en qué medida la policía, las cortes, correcciones, el bienestar de los menores y las agencias de salud mental reflejan nuestros valores e ideologías, como miembros de los grupos que componen la sociedad, o si simplemente las aceptamos sin cuestionarlas.

En qué medida podremos hablar de agencias humanas (Bridges \& Meyers, 1994), como aquellas en las cuales nuestros valores y creencias como individuos, grupos y comunidades, sirvieron para transformarlas y hacer emanar de ellas políticas y programas de beneficio a la sociedad. Contrario a este tipo de instituciones, el esquema del control social que nos ordena, evidencia instituciones que tienden a oprimir y a no evidenciar su propia legitimidad. Para Sparks y Bottoms (1995) las instituciones correccionales presentan un problema crónico de legitimidad que incide, no sólo en su existencia, si no también, en el tratamiento que ofrecen. Este se evidencia en el tratamiento social y sus fracasos, vistos a través de la óptica de que la reincidencia es el ejemplo más concreto de fallas de la propuesta de rehabilitación por parte del estado y su Sistema Correccional. En qué medida están las estructuras dispuestas a recibir de parte de sus clientes internados legitimación. En qué 
medida se está dispuesto a recibir de estos clientes una evaluación de su efectividad.

Ciertamente, instituciones con regímenes y procedimientos justos podrían legitimar su acción y ser más efectivas. Esto no implicaría en perder control ni en complacer a los prisioneros. Implicaría en trabajar en un sistema, no sólo defendible por sus funcionarios, si no también por su clientela que acreditaría en lo que se hace en su bienestar. Provocaría a su vez, un ambiente de prevención y el desarrollo de un tipo de control no obstrusivo que facilitaría la vida al interno en las propias instituciones. Contrario a esto, el control existente no favorece el trabajo necesario y requerido para esta población.

Para Aniyar de Castro (1987) uno de los problemas básicos de las crisis del Sistema Penitenciario es de la misma forma la crisis provocada por la falta de su legitimación, lo que ella llama, una falta de consenso sobre su dominio. Para la referida autora esa crisis se evidencia de la siguiente forma: en el aumento de la delincuencia y la reincidencia, en el contenido de los códigos penales que no se ajustan al grado de desarrollo de la sociedad en el sentido de inseguridad ciudadana, en el acceso a una justicia mal distribuida, al aumento de la justicia en libertad vigilada, al cuestionamiento de los intereses protegidos por la ley, a la selección prejuiciada de internados (mayormente adictos) y en el autoritarismo de la justicia formal.

Sobre todo, le preocupa a la autora, que continúe vigente la noción de que el condenado es el chivo expiatorio que tranquiliza las conciencias y canaliza la violencia. Contrario a todas las implicaciones que a su ver este tipo de control social trae consigo, Aniyar de Castro parece favorecer un tipo de justicia más participativa y propone entre otras cosas, la eliminación del sistema penal. Parker (1997) en un análisis criterioso del sistema de justicia y correccional en Dinamarca, comenta que en ese país se propuso seriamente la eliminación del sistema penal por opciones alternativas en la comunidad. Estas preocupaciones han tenido amplio espacio de reflexión junto a estudiosos como lo son Tittle (1994), entre otros. Propone este autor en lo relacionado al control social, que se analice el mismo desde diversas perspectivas y orientaciones- de consenso- de conflicto y de burocracia- para poder evaluar todo el impacto de las teorías de control social vigentes, en lo que él clasificó, como tratamiento desigual.

Toda esta dimensión de control social y sus diversos efectos inciden también en un alto nivel de frustración con el sistema de justicia 
y su funcionamiento a nivel correccional, de parte de funcionarios, de internos y de la comunidad. De acuerdo a Carey (1996), inclusive las prácticas del propio sistema previenen el que se consiga alcanzar las metas que se propone. Entiende que el debido proceso de ley, base angular del sistema, protege la imposición injusta del poder del Estado, es lento y pasivo; el sistema adversarial, despersonaliza los procesos, causa demoras por su denuncia sobre datos de interés; el procesamiento de casos, donde se minimiza o se ignora la comunicación, tiende a ser impersonal y a no atender las necesidades emocionales de las partes involucradas. Al respecto recalca dicho autor, incidiendo en el análisis que llevamos a cabo, que los problemas que las sociedades experimentan están directamente relacionados a la gente que hace la sociedad. Las causas y las soluciones, entre otros, el problema creciente de criminalidad, de la misma forma, pertenecen a todos.

Es interesante constatar cómo se forja la opinión pública respecto a la aceptación, aparentemente pasiva respecto a "issues" de control social y del funcionamiento de sistema de justicia y correccional y cómo ésta incide en la población penal y su tratamiento. Dicha aceptación, con frecuencia lleva a las personas de la comunidad a reclamar, apoyar, y ciertamente parece irónico, la construcción de nuevas prisiones y a oponerse a los servicios básicos sociales de educación a los pobres, a pesar de que esta intervención es más barata que construir prisiones. Esto es así, cuando lo contrario podría prevenir el crimen (Welch 1995; May \& Vass, 1996). Al respecto, Gagi citado por Welch, quien es director ejecutivo de la Asociación Correccional en New York comenta que, las prisiones se están convirtiendo en los lugares donde se les proveen servicios básicos a la gente pobre, lo que ciertamente conflige con su propósito básico. Es curioso constatar en la época de la globalización, este impacto que refleja una gran pobreza ideológica del sistema, condiciones que años atrás constaté en Brasil y Puerto Rico y que parecían en cierta medida superadas bajo el manto del progreso. Contrario a la expectativa, están recrudecidas, dándonos una señal clara de los altos índices de exclusión social, desigualdad social y opresión a la que se somete la población internada en nuestras instituciones penales, fenómeno este que se observa de la misma forma a nivel mundial.

Esto nos trae al debate de tratamiento social institucional y cómo se traduce éste en rehabilitación, habilitación, o meramente intervención junto a estas poblaciones. Este debate nos lleva necesaria y 
forzadamente a adentrarnos en los aspectos de las filosofías que rigen los sistemas de justicia y correccionales. Al respecto, valga aclarar que en el contexto de Puerto Rico, la noción imperante ha sido la de la filosofía retributiva, la cual por su propia orientación inhibe en gran medida el tratamiento, una vez que su orientación básica es el control y junto a él, el castigo de los internos. Así, esta noción trae consigo un paradigma que reclama cambios y es, encerrar y castigar para rehabilitar; que en sí mismo es una paradoja. Con frecuencia, lo que se observa es que se focaliza todo el esfuerzo en el individuo ofensor y no en los agentes criminógenos de la sociedad que continúan promoviendo por sus efectos, el aumento del crimen (Raynor, 1996, Rivera de Ríos, 1999). Es alarmante en casos, como la propia moral pública predominante, sustentada por el Estado se contrapone a las filosofías de apoyo al Sistema Correccional. Así, lo que los presidiarios ven en los líderes del país ejecutar de forma impune, les ha llevado a ellos al encierro en prisión. Situaciones como éstas son el máximo de la paradoja. Mientras algunos admiten públicamente sus ilegalidades con jocosidad, otros están observando desde las celdas. Es un trastoque de poder, de valores y de legitimidad que trae consecuencias con las cuales se hace difícil lidiar, especialmente en la calidad de la administración de la justicia (Carlson, 1976).

Adentrarnos en el contexto de tratamiento social penitenciario y rehabilitación trae consigo la necesidad de ponderar aspectos de justicia y en qué medida se le percibe a ésta como algo relacionado integradamente a las necesidades humanas (Rivera de Ríos, 1999; Sullivan, 1998). Esto implica en no apartar nuestro análisis de aspectos de la estructura social y cómo ésta influye en nuestras vidas. De la misma forma, no obviar el concepto de violencia social estructural que es la violencia generada por las instituciones sociales hacia las persona, por la misma forma en que están establecidas. No podemos en este sentido obviar el riesgo de la justicia y sus acciones. Hay que interpretarlas y actuar hacia o contra ella.

Esto nos llevará, según Sullivan (1998) a mirar la violencia, no sólo como un acto individual, sino también, cómo y en qué forma la estructura social nos causa daño, nos devalúa, no nos legitima ni apoya. Nos debemos preguntar, si vale la pena apoyar estructuras sociales que nieguen el bienestar humano, o si vamos a apoyar el desarrollo y a promover la creación de arreglos sociales que sean estructuralmente justos para lidiar con los problemas 
de desigualdad social que trae consigo la criminalidad, provocada en gran medida por las propias estructuras sociales apoyadas por el Estado.

La noción de tratamiento social penitenciario ha tenido sus defensores y sus críticos a través de los períodos en que se ha intentado llevar a cabo. Probablemente toda esta discusión se deba, como implicamos antes, a los propios debates sobre conceptualización, filosofías, orientaciones y otros aspectos que no podemos obviar al referirnos a tratamiento y su impacto, porque incide y emana de la propia orientación filosófica adoptada por el Estado. De todas formas, al referirnos a tratamiento social penitenciario, hablamos de los esfuerzos llevados a cabo, por la estructura del Estado, en este caso del Sistema Correccional, para propiciar condiciones de ofrecer a los internos servicios que promuevan y faciliten su rehabilitación o habilitación para volver a la comunidad. Todo este esfuerzo a su vez, requiere del apoyo de leyes del Estado, políticas sociales, programas y servicios institucionales y comunitarios.

La propia propuesta de tratamiento social penitenciario implica en dimensiones, tanto internas como externas, al intentar propiciar modificaciones en el ofensor y ayudarlo a cambiar. Este proceso se da principalmente a través de programas y servicios que sirven como incentivos positivos para propiciar cambios y modificar circunstancias de vida y de la misma forma mejorar oportunidades sociales a través de varias formas programáticas. No implica de ninguna manera, cómo es de conocimiento en este país, en disminuir castigos, traumatizar físicamente o devastar la mente y el cuerpo con técnicas cuestionables de control y seguridad bajo el manto de la rehabilitación. El tratamiento social penitenciario de modo general, intenta afectar el comportamiento futuro del individuo en las actitudes que el individuo tiene hacia sí mismo y en sus interacciones con otros, focalizando en factores y condiciones tales como, técnicas de ajuste individual, desarrollo de intereses y destrezas, superación de limitaciones personales y modificación de circunstancias de vida. Estos énfasis son los que se trabajan a través de los llamados programas institucionales (Palmer, 1992).

Ese tratamiento debe ser no sólo para el interno, si no también, incidir en su familia y en la comunidad. Su efectividad requiere de un cernimiento adecuado al identificar, no sólo sus necesidades, sino también sus debilidades y fortalezas que permitan aprender, crecer y superar etapas o fases de su vida (Stein, 1995, García-Toro, 
$1994,1993,1990,1986,1985)$. Otros autores como Cullen y Gilbert citados por Welch (1995), entienden que hay una serie de razones por las cuales el tratamiento orientado a la rehabilitación debe ser reafirmado, son éstas:

1. Es la única justificación de la sanción criminal que obliga al Estado a cuidar por el bienestar y las necesidades del ofensor;

2. La ideología de la rehabilitación provee una racional importante para oponerse a los conservadores que piden aumento de la represión para erradicar el crimen;

3. La rehabilitación todavía recibe considerable apoyo como una meta relevante del Sistema Correccional y por último, porque históricamente ha sido motivo importante bajo los esfuerzos de reforma que han orientado la humanidad del Sistema Correccional.

Para Palmer (1992), la meta de la ley penal es proteger la seguridad pública y promover el orden y estabilidad de la sociedad. Es a través del Sistema Correccional que se consigue rehabilitar o habilitar en el sistema vigente de nuestra sociedad. Esta perspectiva hace necesario el bosquejar y trabajar los contenidos más importantes de las áreas a ser objeto de intervención, entre las cuales sobresalen las siguientes:

1. Las circunstancias de la vida actual del ofensor, incluyendo presiones o recursos particulares del ambiente y cómo se dirigen a ellos para satisfacerlos o trabajarlos.

2. Tipos y fuentes de motivaciones e intereses del ofensor.

3. Destrezas, limitaciones y principales miedos del ofensor.

4. Movidas iniciales inmediatas: tipos de modos de vida en programas de base comunitarias y si el regreso inmediato a la escuela es recomendable o realista.

5. Sentimientos y actitudes en relación a otros significativos, defensas y otras técnicas y patrones críticos utilizados.

6. Métodos o técnicas a las cuales e individuo pueda responder positiva o negativamente.

7. Tiempos y prioridades.

8. Roles y necesidades del personal. 
Visto así, el tratamiento social penitenciario o intervención, es un proceso sumamente complejo que involucra todas las dimensiones de vida del individuo, las familias y la comunidad. Es por estas razones entre otras, que a los elaboradores de política pública se les hace tan difícil reconocer, aportar y apoyar este proceso de tan múltiples interrelaciones. El mismo requiere que el Sistema Correccional examine cuidadosamente su compromiso y lo que implica aceptarlo para la población internada, su familia y la comunidad. Sería interesante que en ese proceso de validación, el administrador(a) del Sistema Correccional se dirigiese al público con relativa frecuencia para informar al pueblo de su quehacer, sus logros, fracasos, dificultades y expectativas. Este tipo de acción legitimaría su tarea y a la larga conseguiría mayor apoyo de la comunidad, pues lo desconocido genera, por su propia naturaleza, incertezas y desconfianzas.

Con frecuencia se percibe de parte del público una sensación de que en el Sistema Correccional se le falta el respeto a la ley y en ocasiones, la sensación de que las crisis son por ellos mismos provocadas (Skatnicki, 1998). Esto ha traído consigo toda una corriente de interés por el desarrollo de tratamiento en el contexto de las comunidades, fuera de las estructuras prisionales, opresivas por naturaleza. Esta perspectiva, de la misma forma ha sido evaluada evidenciando tanto sus limitaciones como sus virtudes, pero en si misma no es la única solución. Con frecuencia sus acciones son por demás intromisorias en el contexto carcelario, como es el caso de los grilletes en el contexto familiar (Parker, 1997, Rayor, 1996, Rogers \& Jolen, 1992, Rivera de Ríos, 1996).

Tanto el ofrecimiento de servicios correccionales dentro de instituciones penales como los servicios correccionales a nivel comunitario, son parte integrante del mismo sistema. Los servicios de corrección a nivel comunitario se refieren de modo amplio, a estrategias correccionales para mantener los ofensores fuera en la comunidad, en oposición a la prisión. Son más comunes y llevan consigo hoy día, gran parte del peso del Sistema Correccional. De la misma forma, ofrecen la oportunidad de alternativas de tratamiento más novedosas y viables y más costo-efectivas que las que se llevan a cabo en los ambientes prisionales cerrados (Del Carmen, 1992).

Toda propuesta de tratamiento para ser efectiva requiere no sólo el adecuado apoyo presupuestario, si no también, la dirección y apoyo de paradigmas que la viabilicen y generen el ambiente y las 
actividades requeridas. Entendemos por paradigma, un modelo o patrón que contiene un conjunto legítimo de supuestos para recoger e interpretar información (Ander-Egg, 1995; Baker, 1995). Siendo así, los paradigmas son básicos a todo tratamiento y es necesario reconocerlos para entender los efectos provocados. En fin, la orientación de estos sistemas no surge de la nada. Unbriet (1994) defensor del enfoque restaurativo, entiende que los paradigmas son básicos, tanto en la orientación del Sistema Correccional y el de Justicia y así siendo, reflejan e imparten orientaciones al tratamiento social institucional. La coherencia de ambos es lo que promueve este último autor. Siendo así, recomienda una serie de paradigmas que paso a compartir con ustedes, a título de Paradigmas para el Sistema de Justicia que redundaría en aspectos positivos para el Sistema Correccional y sus propuestas de manejo de la población bajo su custodia y control.

1. El crimen se debe definir como una violación de una persona a otra (no contra el Estado).

2. El foco de solución de los problemas, en lo que respecta a responsabilidades y obligaciones, es prospectivo (no se basa en la culpa, ni en el pasado).

3. La negociación y el diálogo son la norma (no el proceso adversarial).

4. La restitución debe ser vista como modo de restauración de ambas partes y su meta debe ser la reconciliación/restauración (no la imposición de castigos).

5. La Justicia debe ser definida a través de relaciones adecuadas, y juzgada por resultados o producto, no sólo por reglas.

6. Reconocer el crimen como un conflicto interpersonal; y reconocer el valor del conflicto (no el conflicto entre el individuo y el Estado).

7. Foco de atención debe estar centrado en la reparación social.

8. La comunidad debe ser vista como facilitadora en el proceso restaurativo y no como un obstáculo.

9. Promoción de la mutualidad y no la individualidad.

10. El papel del ofensor y de la víctima se reconocen en la solución del problema: derechos de la víctima, reconocimiento de sus necesidades; se motiva a los ofensores a asumir responsabilidades (es un proceso activo y no pasivo). 
11. La responsabilidad del ofensor se define como entender el impacto de la acción y ayudar a decidir cómo hacer las cosas bien (y no castigar al ofensor).

12. El ofensor se ve como un todo en el contexto: moral, social, económico y político.

13. Las nociones de deuda/responsabilidad deben ser reconocidas por la víctima (no la deuda al Estado y la sociedad).

14. Respuestas focalizadas en las consecuencias dañinas del comportamiento del ofensor (y no en el pasado de éste).

15. El estigma del crimen se remueve a través de la acción restaurativa (no se ve como algo irreversible).

16. Posibilidades reales de arrepentirse y perdonar (y no el imposibilitarlo).

17. Envolvimiento directo de los participantes (no depender de la representación de profesionales necesariamente).

Ciertamente esta propuesta de paradigmas nos lleva a la tercera parte de este trabajo que es la de recomendaciones.

\section{Recomendaciones}

El tema de tratamiento social penitenciario tan someramente tratado, no se agota en este trabajo. Ciertamente, la realidad puertorriqueña nos coloca en perspectiva al constatar en los rotativos del país, problemas sociales y situaciones que denotan un marcado "aumento en los Delitos Tipo Uno" (Hernández, 1999) y acciones como la posposición de la política, "una falta y estas fuera" (Serrano, 1999). Estas noticias inciden en el panorama que nos preocupa e interesa, en la marginación y exclusión social, que las estructuras del Estado, en su afán de implementar políticas, provocan en el pueblo.

Todo esto nos lleva a pensar que la mejor recomendación que puede ser hecha al Sistema de Justicia puertorriqueño y el correccional, es que consideren seriamente un cambio en la orientación filosófica que apoya sus acciones. Este cambio sería hacia una orientación de justicia restaurativa. Ésta provee un marco de referencia totalmente diferente para responder al crimen (Ubriet, 1994). En vez del Estado ser definido como la víctima, la justicia restaurativa postula que el comportamiento criminal es primero un 
conflicto entre individuos. En primera instancia está la persona violada o víctima y en un lugar secundario el Estado.

La justicia restaurativa se rehúsa a usar el poder, el control y la violencia como medios para la corrección (Sullivan, Tifft \& Cordella, 1998). Se le conoce como una justicia transformadora, una que procura efectuar cambios a nivel estructural, apoyando arreglos sociales que son vitales al tomar en cuenta las necesidades básicas de todos. A muchos, según los referidos autores, le causa preocupación la vinculación entre la justicia restaurativa y la transformación social. Ciertamente asume una dimensión de dinamismo que es contraria a la sustentación del "estatus quo" y sus consecuencias, a pesar de toda la preocupación con su legalidad y moralidad.

Para estudiosos del campo de la política social como el Dr. David Gil, citado por Sullivan (1998), el proceso restaurativo y transformador puede inclusive ser clave en la solución de problemas como lo es la violencia familiar. Implica en propiciar de forma estructurada el tomar en cuenta las necesidades de todos y participar plenamente en las discusiones que afectan el deseo de vivir de las personas. Es transportar la justicia al seno de la familia, unidad institucional base de la sociedad, tal vez, propiciando el salir de la jerarquización y del poder, como modelo y paradigma de justicia en nuestra sociedad.

Esta propuesta no es nueva, surge en Canadá, alrededor de la década del 1970 y es entonces cuando repercute en los Estados Unidos (Daly \& Immarigeon, 1998). Su énfasis desde entonces, fue el reparar los daños y la reapertura de vínculos sociales resultados de actos criminales, se focaliza en la relación entre víctimas del crimen, ofensores y sociedad, lo que presume cambios a diversos niveles de acción. Algunos ejemplos de programas orientados en esta dirección lo han sido: derechos de los presos y alternativas de prisión, programas de reconciliación de víctimas y ofensores, mediación entre ofensores y víctimas, defensa de las víctimas, conferencias de grupos familiares, circuitos de sentencia y otras prácticas novedosas de los años '90.

Para Zehr \& Mika (1998) la justicia restaurativa se compone de tres elementos básicos, a saber:

1. El crimen es fundamentalmente una violación de gente y relaciones interpersonales.

2. Las violaciones crean obligaciones y demandas.

3. La justicia restaurativa procura sanar y acertar errores. 
Es un proceso amplio, donde el propio proceso judicial maximisa oportunidades de intercambio de informaciones, participación, diálogo y consentimiento mutuo entre víctima y ofensor. El proceso de justicia restaurativa pertenece a la comunidad.

Para Marshal, citado por Zehr \& Mika, la justicia restaurativa es un proceso a través del cual todas las partes con incumbencia en la ofensa en particular, se unen para resolver colectivamente cómo lidiar con los efectos de una ofensa y sus implicaciones futuras, en fin, es un proceso colaborativo para resolver daños. De acuerdo a los autores citados, se está trabajando hacia una justicia restaurativa:

1. Cuando focalizamos en los daños de la acción errada más que en las reglas que se quebraron en el proceso.

2. Cuando se demuestra igual preocupación y compromiso a las víctimas y a los ofensores, involucrando ambos en el proceso de justicia,

3. Cuando se trabaja hacia la restauración de las víctimas empoderándolas y respondiendo a sus necesidades como ellos las ven,

4. Cuando se apoye al ofensor mientras se le motiva a entender, aceptar y cumplir con sus obligaciones,

5. Cuando se reconozca que nuestras obligaciones pueden parecer difíciles a los ofensores, ellas no deben ser vistas como daños y deben ser alcanzables,

6. Cuando se provean oportunidades de diálogo directo e indirecto, entre víctimas y ofensores, según sea apropiado,

7. Cuando se involucre y empodere la comunidad afectada a través del proceso judicial y se aumente la capacidad de reconocer y responder a las bases comunitarias del crimen,

8. Cuando se motive la colaboración y la integración, en vez de la coerción y el aislamiento,

9. Cuando se preste atención a las consecuencias no intencionadas de nuestras acciones y programas, y cuando

10. Se muestre respeto a todas las partes, incluyendo las víctimas, los ofensores y a los colegas de justicia.

Ciertamente, no es una propuesta inviable a pesar de parecer difícil, tal vez es hora de dar espacio a nuevas alternativas. La realidad 
social de nuestro país evidencia diariamente que ni el derecho penal, ni la justicia, ni correcciones están siendo afectivas y menos costo eficientes. Desafíos como éste merecen ser re-pensados.

Súmensele a esta recomendación para lidiar con las condiciones actuales, las siguientes:

1. Existe una crasa necesidad de darle ayuda profesional a jóvenes y adultos, hombres y mujeres, que regresan a sus casas y a sus comunidades sin ningún tipo de apoyo luego de haber estado internados en instituciones correccionales de adultos y jóvenes. Tanto las familias como las comunidades deben estar preparadas para lidiar efectivamente con este impacto. Los estudios demuestran que los índices de reincidencia son significativamente más bajos cuando se provee este tipo de apoyo (Daum, 1992).

Detrás de esta recomendación está la necesidad de romper de una vez con el paradigma de instituciones vs. la libre comunidad. Se necesita integrar la institución correccional a la noción de comunidad y abrir puentes entre éstas, para que el proceso sea uno de dos vías de apoyo: institucional y comunitario. Los trabajos de la Dra. Trina Rivera de Ríos (1999, 1996, 1990) han sido un alerta constante a la relevancia de este binomio.

2. Los criminólogos del país como los estudiosos del derecho penal, abogados, sociólogos, trabajadores sociales y otros profesionales de la conducta, deben añadir en la lista de variables intervinientes que inciden en los problemas sociales del país, sus gentes y sus comunidades, al gobierno. Se debe prestar atención velada al problema social del gobierno y a la dimensión estructural del problema. Es una población que merece estudio. Son los actores del desarrollo de políticas públicas. Sin este análisis de cómo el gobierno juega su papel guiando, orientando y afectando la práctica y el debate sobre las personas, el tratamiento y el impacto del derecho penal estaría incompleto. Es tiempo de discutir el papel del gobierno en definir o caracterizar el tipo de sociedad en que uno vive. Este análisis debe ser extendido a la política y práctica penal de forma adecuada y sistematizada (Vass, 1996).

3. Finalmente, recogiendo las palabras de estudiosos como 
Sullivan (1998) y Rivera de Ríos (1999) debemos aprender a ver la justicia como algo integradamente relacionado a las necesidades humanas y examinar crítica y criteriosamente cómo esta incide en nuestras vidas como individuos, miembros de una familia y de una comunidad. Es deber ciudadano luchar por una mejor y más efectiva justicia para todos.

\section{Referencias}

Ander-Egg, E. (1995). Diccionario de trabajo social. Argentina: Editorial Lumem, 215-216.

Aniyar de Castro, L. (1987). Criminología de la liberación. Venezuela: Editorial de la Universidad de Zulia.

Baker, R.L. (Ed.). (1995). The social work dictionary (3rd ed.). Washington: NASW Press.

Bloom, B. (1998, December). Beyond Recidivism. Perspectives on evaluation of programs for female offenders in community Corrections. The ICCA Journal, 32-35.

Bridges, G.S. \& Meyers, M.A. (Eds.). (1994). Inequality, crime and social control. San Francisco: Westview Press.

Buckley, K. (1996). Masculinity, the probation service \& the causes of offending behavior. In T. May \& A. A. Vass (Eds.), Working with offenders (96-115. London: Sage.

Carey, M. (1996, August). Restorative justice in community corrections. Corrections Today, 58(5), 152-155.

Carlson, R.J. (1976). The dilemas of corrections. London: Lexintong Books.

Carter, R.M., Cocks, J. \& Glaser D. (1992). Community service: a review of the basic issues. In T. Ellsworth (Ed.). Contemporary community corrections (pp. 297-309). Illinois: Waveland Press.

Colón Rodríguez, F. (1979). Servicios médicos en las penitenciarías, aspecto esencial de la rehabilitación. Ponencia Inédita presentada en Congreso sobre Criminalidad, Colegio de Abogados, Santurce, Puerto Rico.

Daly, K. \& Immarigeon, R. (1998). The past, present and future of restorative justice: Some critical reflections. Contemporary Justice Review, 1(1), 21-46. 
Davidson, W.S., Redneer, R., Amdur, R.L., Mitchel C.M. (1990). Alternative treatments for troubled youth. New York: Plenum Press.

Departamento de Justicia. (1990). El uso de drogas y su relación con la conducta delictiva. Estudio Inédito del Departamento de Justicia de Puerto Rico.

Daum, J.M. (1992). Aftercare, the neglect phase of adolescents. In T. Ellsworth (Ed.), Contemporary community corrections (pp. 207-214). Illinois: Waveland Press.

García Toro, V.I. (1994). Reflexiones en torno a la delincuencia juvenil en Puerto Rico y aspectos de prevención. Conferencia inédita presentada ante Junta de Educación de la Ciudad de New York. Presidencia, UPR, Río Piedras, Puerto Rico.

García Toro, V.I. (1993). Aspectos bio-psico-sociales de la Criminalidad. En L. E. Maldonado \& B. Rivera (Eds.). Análisis, reflexión y acción psicológica ante la violencia y la criminalidad en Puerto Rico. Río Piedras: Asociación de Estudiantes de Sicología de Puerto Rico, Inc.

García Toro, V.I. (1990). Trabajo Social y Modelos Penitenciarios.

Revista da Escola Do Servico Penitenciario do Rio Grande do Sul: 1(5), 75-92.

García Toro, V.I. (1986). La familia y la comunidad: Perspectivas de cambio y alternativas de acción y modelo de acción comunitaria o modelo de acción social puertorriqueña. Ponencia presentada en Porto Alegre, Brasil.

García Toro, V.I. (1985). Consideraciones relativas a la rehabilitación del confinado y su impacto en el ajuste a la comunidad: Trabajo. Conferencia presentada en ADT, Departamento del Trabajo, San Juan, PR.

Hernández, M. (1999, Junio 14). El Crimen no Para. Primera Hora, p. 2.

May, T. \& Vass., A.A. (1996). Working with offenders. London: Sage Publications.

McCorkle, R.C. (1993). Research note: Punish \& rehabilitation. Public attitudes towards sex common crimes. Crime E' Delincuency, 39(2), 240-252.

Palmer, T. (1992). The re-emergence of correctional intervention. London: Sage Publication.

Parker, C.D. (1997). A contemporary view of alternatives to incarceration in Denmark. Federal Probation, LX1, (2), 69-73.

Picó, F. (1994). El día menos pensado. Río Piedras: Ediciones Huracán, Inc. Platt, A.M. (1994). Rethinking and unthinking social control. In C. S. Bridges \& M. A. Meyers (Eds.), Inequality, crimen and social control (pp. 72-79). San Francisco: Westview Press. 
Raynor, P. (1996). Evaluating probation: The rehabilitation of rffectiveness. In T. May \& A.A. Vass (Eds.), Working with offenders, (pp. 242-258). London: Sage Publications.

Rivera de Ríos, T. (1999). Sistema de bienestar social. ¿Estado opresivo y destructivo de pueblos-gente? Impacto en el sistema correccional de Puerto Rico. Ponencia presentada en $11^{\text {ava.. }}$ Conferencia Dorothy D. Bourne, Escuela Graduada de Trabajo Social, Universidad de Puerto Rico, San Juan, PR.

Rivera de Ríos, T. (1996). Ponencia de la C. 1629. Ponencia del Comité Amigos y Familiares de Confinados, Inc.

Rivera de Ríos, T. (1990). Effects of the HIV Epidemic on the Commonwealth of Puerto Rico: Perspectives on issues related to HIV services for persons with HIV Infection and AIDS. Ponencia Inédita ante Comisión Nacional de AIDS. Vistas Públicas, 27 de noviembre de 1990.

Rivera de Ríos, T., Feliberti de Robles, D. \& Torres de Padilla I. (1999). Ponencia R. Del S 1487. Ponencia en apoyo a propuesta de Senadora Mercedes Otero de Ramos.

Rogers, R. \& Jolin, A. (1992). Electronics monitoring: A review of the empirical literature. In T. Ellsworth (Ed.), Contemporary community corrections (pp. 310-321). Illinois: Waveland Press Inc.

Schichor, D. (1992). Following the psicological pendulum: The survival of rehabilitation. Federal Probation, LVI (2), 19-25.

Serrano, O. J. (1999, Junio 14). Paralizan hasta agosto "una falta y estás fuera". Primera Hora, p. 13a..

Sparks, J. R. \& Bottons, A.E. (1995). Legitimacy and order in prisons. The British Journal of Sociology, 46(1), 45-62.

Skatnicki, A.C. (1998, December). Continuity \& change in the pursuit of criminal justice. The ICCA Journal, 10-15.

Sluder, R.D. \& Sapp A.D. \& Langston D.C. (1994). Guiding philosophies

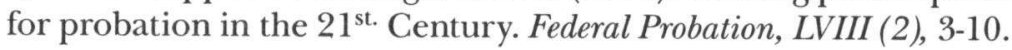

Stein, J.A. (1995). Residential treatment of adolescents $\mathcal{E}$ children. Chicago: Nelson Hall Publisher.

Sullivan, D. (1998). Welcome to this forum. In D. Sullivan (Ed.), Contemporary Justice Review, 1(1), 1-6.

Sullivan, D., Tafft, L. \& Cordella, P. (1998). The phenomena of restorative justice: Some Introductory remarks. Contemporary Justice Review, $1(1), 7-20$.

Swartz, J.A., Lurigio, A. G. \& Slonka, S.A. (1996). The impact of IMPACT on assessment of the effectivenes of Jail Based Treatment Program. Crime Ẽ Delincuency, 42(2), 553- 573. 
Tittle, C.R. (1994). The theoretical bases for inequality in formal social control. In C. S. Bridges \& M. A. Meyers, (Eds.), Inequality, crime $\mathcal{E}^{\circ}$ social control (pp. 21-52). San Francisco: Westview Press.

Vass, A.A. (1996). Community penalties: The politics of punishment in May, T. \& Vass, A.A. (Eds.), Working with offenders (pp. 157-184). London; Sage Publications.

Von Hirsh, A. (1992). The ethics of community based communities. In T. Ellsworth (Ed.), Contemporary community corrections (pp. 429-440). Illinois: Waveland Press Inc.

Unbreit, M.S. (1994). Victim meets offender. New York: Willow Tree Press, Inc.

Welch, M. (1995). Rehabilitation: Holdings it's ground in Corrections. Federal Probation, LIX (4), 3-8.

Zehr, H. \& Mika, H. (1998). Fundamental concepts in restorative justice. Contemporary Justice Review, 1(1), 47-55. 